\title{
Turbocharged Juul device challenges European tobacco regulators
}

To the Editor:

In October 2019 an executive sacked by the electronic cigarette company, Juul, filed a lawsuit against his former employer alleging a cover-up of the sale of one million e-cigarette pods filled with contaminated flavoured nicotine liquids $[1,2]$. The lawsuit also claimed that Juul was developing a "Turbo" version of their product for markets that limit nicotine levels. A new study by a team of the German Institute for Risk Assessment (BfR) revealed that "Turbo" Juul devices have, in fact, been marketed in Europe since summer 2019 [3].

Juul's success in the USA has been attributed to a liquid formulation containing as much as $59 \mathrm{mg} \cdot \mathrm{mL}^{-1}$ (5\%) nicotine, resulting in much higher peak nicotine levels in blood of users than delivered by previous devices [4]. In Europe, the EU tobacco products directive limits nicotine levels in the liquids vaporised by e-cigarettes [5]. The Juul pods initially marketed in the EU contained $20 \mathrm{mg} \cdot \mathrm{mL}^{-1}(1.7 \%)$ nicotine, the maximal allowed level. Compared to the USA, Juul has only gained a modest share of the EU market. Consumers likely didn't care for the EU-marketed devices that were technically identical to Juul's US devices, but delivered only about one-third of the nicotine.

The lawsuit suggests that Juul explored technical solutions to deliver more nicotine to users while not violating the EU's limitations [1]. According to the BfR team, Juul altered device characteristics by inventing a new type of wick, the fabric string carrying the e-liquids from the reservoir to the heating coil [3]. The devices with the altered wick, marketed in Europe since summer 2019 with e-liquid nicotine content of either 18 or $9 \mathrm{mg} \cdot \mathrm{mL}^{-1}$, delivered almost three times as much nicotine as the previous model, similar to levels delivered by US-marketed products [3]. The change in wick design achieved this by delivering vapour with an almost three-fold increased aerosol density. Battery voltage and other key technical attributes remained identical to the US version, before and after introduction of the "Turbo" version [6,7]. The authors found that the new model produced higher levels of acetone in the dense vapor, but lower levels of other carbonyls, suggesting that additional studies are required to evaluate potential changes in respiratory toxicity of the new model [3].

Juul didn't stop there. The company also altered the flavour composition of one of its key varieties, menthol, likely adapting to consumer preferences in the European market. A chemical analytical study by a team from Yale and Duke (co-authored by S-E. Jordt), found that menthol levels were reduced in European Juul, replaced by a synthetic cooling agent, WS-3 [6]. Cooling agents such as WS-3 lack the minty odour of menthol but impart the same cooling sensation and are less irritating than menthol. Agents such as WS-3 present a unique challenge to the concept of "characterising flavours" that governs the regulation of flavours by the EU tobacco product directive. Since they are odourless, synthetic cooling agents will evade the proposed European testing paradigm for characterising flavours that relies on odour detection by a testing panel $[8,9]$. Juul likely replaced menthol with WS-3 because European consumers found high levels of menthol aversive. However, the company still wanted to ensure a similar cooling effect, known to facilitate initiation. Cooling agents such as WS-3 may be used by the industry as replacements for menthol since they don't register as a characterising flavour and would not violate a menthol ban if imposed on e-cigarettes. While the EU ban for menthol in combustible cigarettes went into effect this May, a recent study detected WS-3 cooling agent in combustible cigarettes, and additional e-cigarette varieties marketed in Germany [10].

@ERSpublications

Juul, the e-cigarette company, re-engineered their device for the European market, increasing nicotine delivery to US levels and adding a synthetic cooling agent to replace menthol. This approach takes advantage of insufficient EU tobacco regulation. https://bit.ly/3iixAhU

Cite this article as: Jabba SV, Jordt S-E. Turbocharged Juul device challenges European tobacco regulators. Eur Respir J 2020; 56: 2002430 [https://doi.org/10.1183/13993003.02430-2020]. 
With the new EU-marketed Juul devices delivering much higher amounts of nicotine, and addition of an odourless cooling agent making vaping more palatable, the spectre of a vaping epidemic among the youth and young adults of Europe is becoming a concern. How can the EU respond to a company determined to make its product as addictive as possible? Limiting nicotine concentrations in e-liquids is clearly insufficient, since manufacturers remain free to alter delivery volumes and frequencies. Regulators should consider limiting the amount of nicotine delivered in each puff, no matter the volume, and limit the frequency of a device to deliver puffs. These measures would restrict the absolute amount of nicotine a user is taking in over time, and limit the potential to develop dependence.

EU regulators need to acknowledge that modern flavour chemistry has the tools available to out-manoeuvre the outdated regulatory concept of "characterising flavours". This concept needs to be revised or replaced with an alternative approach, such as a positive list of permitted ingredients.

Sairam V. Jabba $\oplus^{1}$ and Sven-Eric Jordt $\oplus^{1,2,3}$

${ }^{1}$ Dept of Anesthesiology, Duke University School of Medicine, Durham, NC, USA. ${ }^{2}$ Dept of Pharmacology and Cancer Biology, Duke University School of Medicine, Durham, NC, USA. ${ }^{3}$ Duke University Integrated Toxicology and Environmental Health Program (ITEHP), Durham, NC, USA.

Correspondence: Sven-Eric Jordt, Dept of Anesthesiology, Duke University School of Medicine, 3 Genome Ct, Durham, NC 27710-3094, USA. E-mail: sven.jordt@duke.edu

Received: 21 June 2020 | Accepted: 25 June 2020

Conflict of interest: S. Jabba reports grants from Yale TCORS (U54DA036151), during the conduct of the study. S-E. Jordt reports grants from National Institute on Drug Abuse (NIDA; U54DA036151) and National Institute of Environmental Health Sciences (NIEHS; R01ES029435), during the conduct of the study; personal fees for consultancy from Hydra Biosciences and Sanofi, provision of research materials from GlaxoSmithKline, outside the submitted work.

Support statement: This work was supported by grant U54DA036151 from the National Institute on Drug Abuse (NIDA) and grant R01ES029435 from the National Institute of Environmental Health Sciences (NIEHS) of the National Institutes of Health (NIH) and the Center for Tobacco Products of the US Food and Drug Administration (FDA). The sponsors had no role in the design and conduct of the study, collection, management, analysis, and interpretation of the data, preparation, review, or approval of the manuscript and decision to submit the manuscript for publication. Funding information for this article has been deposited with the Crossref Funder Registry.

\section{References}

1 Dhillon HK, Fleming MR. Siddharth Breja, an individual, Plaintiff, v. Juul Labs, INC., a Delaware corporation. 2019 www.documentcloud.org/documents/6532907-Breja-v-Juul-Lawsuit.html Date last accessed: 09 April 2020.

2 Mahase E. Juul shipped a million contaminated e-cigarette pods, claims lawsuit from former employee. BMJ 2019; 367: I6333.

3 Mallock N, Trieu HL, Macziol M, et al. Trendy e-cigarettes enter Europe: chemical characterization of JUUL pods and its aerosols. Arch Toxicol 2020; 94: 1985-1994.

4 Hajek P, Pittaccio K, Pesola F, et al. Nicotine delivery and users' reactions to Juul compared with cigarettes and other e-cigarette products. Addiction 2020; 115: 1141-1148.

5 Directive 2014/40/EU of the European Parliament and of the Council of 3 April 2014 on the approximation of the laws, regulations and administrative provisions of the Member States concerning the manufacture, presentation and sale of tobacco and related products and repealing Directive 2001/37/EC. Official Journal of the European Union 2014; L127: 1-38.

6 Erythropel HC, Anastas PT, Krishnan-Sarin S, et al. Differences in flavourant levels and synthetic coolant use between USA, EU and Canadian Juul products. Tob Control 2020; in press [https://doi.org/10.1136/ tobaccocontrol-2019-055500].

7 Talih S, Salman R, El-Hage R, et al. A comparison of the electrical characteristics, liquid composition, and toxicant emissions of JUUL USA and JUUL UK e-cigarettes. Sci Rep 2020; 10: 7322.

8 Krüsemann EJZ, Lasschuijt MP, de Graaf C, et al. Sensory analysis of characterising flavours: evaluating tobacco product odours using an expert panel. Tob Control 2019; 28: 152-160.

9 Krüsemann EJZ, Wenng FM, Pennings JLA, et al. Sensory evaluation of e-liquid flavors by smelling and vaping yields similar results. Nicotine Tob Res 2020; 22: 798-805.

10 Reger L, Moß J, Hahn H, et al. Analysis of menthol, menthol-like, and other tobacco flavoring compounds in cigarettes and in electrically heated tobacco products. Contr Tob Res 2018; $28: 93$. 